Geopolítica(s) Revista de estudios sobre espacio y poder ISSN: 2172-3958

\title{
La evolución del Bloque Nacionalista Galego, desde la perspectiva del
} "lugar"

María Lois (2015) Construir Galicia(s). Lugar, elecciones y política nacionalista. Madrid: Trama editorial. 291 pp. ISBN 978-84-943800-7-5.

El análisis de la evolución de una formación política nacionalista, el Bloque Nacionalista Galego (BNG), constituye el objeto principal de este trabajo de María Lois, cuya labor investigadora se ha demostrado ya muy innovadora en el campo de la geografía política y cultural. La originalidad del mismo se encuentra en que su enfoque es muy distinto del habitual en la Ciencia Política y en los estudios electorales, ya que parte para ese propósito de la perspectiva de lo que se ha dado en llamar el "giro espacial": en palabras de John Agnew, desde ese enfoque se propone interpretar el comportamiento político como "el producto de la agencia estructurado a través de los contextos sociales donde las personas viven sus vidas" ( $p$. 24). Una perspectiva de "lugar" que parte de considerar éste como "estructurador de la vida social", frente al estatismo metodológico predominante.

Siguiendo a Agnew, Lois nos propone distinguir tres dimensiones: el "espacio local", la "ubicación" o "localización" y el "sentido del lugar" (p. 22-25). A partir de esa perspectiva y de la búsqueda de los diferentes marcadores empíricos que permitan recoger sus distintas dimensiones, la autora se centra en las experiencias locales de Allariz y Fene con el fin de valorar hasta qué punto el BNG ha desarrollado un sincretismo representacional. Su estudio abarca todo el período que se desarrolla desde 1977 hasta 2002 y por eso no aborda fases posteriores como la experiencia del gobierno bipartito con el PSOE y el relativo declive que se inicia a partir de entonces.

Antes de entrar en los casos mencionados y después de una referencia general a los conceptos de "nacionalismo" y de "nación", así como a los principales enfoques en torno a los mismos, si bien de una forma demasiado sucinta, Lois nos ofrece un recorrido pormenorizado por la historia del BNG, con sus sucesivas etapas (de un frente con un modelo asambleario a un partido semejante a los de tipo convencional), el papel protagonista en su seno de una organización que se reclama del marxismo-leninismo, Union do Povo Galego (UPG), y a su vez el liderazgo carismático de Xosé Manuel Beiras, cuyas tesis sobre la dependencia colonial de Galicia, ya expuestas en una obra emblemática en 1972, servirán de referencia teórica al nacionalismo gallego. Así mismo, describe la progresiva construcción de las organizaciones sociales - principalmente, las sindicales, tanto industriales como 
agrarias, pero también las estudiantiles y otras - que forman parte del mundo del nacionalismo gallego. Sigue luego el análisis de los resultados que ha ido alcanzando esta formación en los sucesivos procesos electorales, a través de los cuales la autora va diseñando una geografía muy detallada del voto al BNG y de los factores que pueden ayudar a explicar su evolución, constatando cómo se va adaptando a diferentes "lugares" y distintos tipos de apoyo.

Lois procede también, como corresponde, a contextualizar esta investigación comprobando que en el ámbito gallego y entre el electorado del BNG no hay una identificación mayoritaria nacionalista pero sí una conciencia de "pueblo diferenciado" (p. 90), que se convierte en aglutinante y se articula a su vez con la dimensión centro-periferia, no solo a escala estatal sino también en relación con el proceso de "integración europea" y la Unión Europea en particular.

Estas particularidades ayudan a entender la evolución del discurso de esta formación, no basándose únicamente en un discurso identitario, y a su vez explican la tensión progresiva que se va generando en su seno, característica de todos los partidos, entre la lógica de la representación y la que le va empujando a la competición electoral con otras fuerzas políticas. Con mayor razón cuando en su aspiración creciente a ser alternativa de gobierno se ha visto confrontada tanto a un Partido Popular (PP), que dio pronto un giro importante hacia un "regionalismo moderado" (p. 93) y autonomista bajo el liderazgo del veterano exministro franquista Manuel Fraga, como al PSOE, considerado convencionalmente como la principal fuerza de izquierdas pese a su adaptación creciente al neoliberalismo pero que, en cambio, sigue siendo percibido como un partido estatalista.

Lois subraya tres etapas en el BNG: la de su inicial configuración como alternativa opositora a lo largo de los años 1980 y principios de los 1990; la de su progresiva conformación como alternativa de gobierno en el marco autonómico durante los años 1990 y, finalmente, la de su conversión de frente a partido en los años 2000. A lo largo de todo este proceso podemos ir comprobando cómo el BNG no se basa solo en un voto identitario nacionalista sino también en su disposición a responder a distintos tipos de electorado y a diferentes "lugares" en función de las particularidades que ofrecen cada uno de ellos. De ahí la tesis de que hay muchas Galicias y de que el BNG ha implementado diferentes prácticas políticas en su propio proyecto de construcción de Galicia como Nación.

Esa tesis se encuentra verificada en Allariz y Fene. En el primero, municipio rural cercano a la capital de la provincia de Ourense, encontramos una "villa icono", un "lugar" moral simbólico, ya que se ha convertido en "la imagen proyectiva de una cosmovisión del nacionalismo gallego", según la define Pereiro Pérez (p. 196). Recordemos además que su alcalde durante un largo período es Anxo Quintana, quien luego se presentaría como candidato a la presidencia de la Xunta de Galicia en 2005, reconociéndose en él una amplia mayoría del BNG y proclamando él mismo su aspiración a "convertir Galicia en lo que hice en Allariz" (p. 153). En cambio, en Fene, cercano a Ferrol, la práctica política tiene que ver más con la evolución de las condiciones de empleo y de vida de la zona del sector naval en la que está ubicado y en cómo el particular colectivo que allí se va conformando, Avante, va actualizando su discurso y su práctica local, pese a las reticencias de la dirección del BNG, ante las circunstancias cambiantes y el peso mayor que considera hay que dar a la "calidad de vida" como referente político. 
En Allariz nos encontramos con sus particularidades rurales y con la singular presencia veraniega de una emigración que trabaja en el País Vasco. El estallido de un conflicto en 1989 en torno a la lucha contra la contaminación del río Arnoia mediante un encierro en el Ayuntamiento constituye un verdadero punto de inflexión en su historia reciente y al mismo tiempo factor de polarización local en su memoria colectiva. Justamente desde las elecciones de octubre de ese año el BNG se convertiría en la primera fuerza política por mayoría absoluta durante largo tiempo. Como bien resume la autora, "la trayectoria del BNG en Allariz, y el cambio de gobierno que se produce en 1989, está ligado a cuestiones de movilización en torno a una reconstrucción del espacio local a través de la proyección de una identidad nacional distintiva (...); los procesos de rehabilitación de los espacios de Allariz han partido de la resemantización de tres elementos presentes en el espacio local (la Historia, la Naturaleza y la situación respecto a Ourense), de su resignificación a través de la práctica política del BNG (...). El conflicto de 1989, el denominado espíritu de Allariz, es fundamental en la habilitación de los significados de los referentes de la villa, cuya patrimonialización se hace en base a la exclusión de ciertas prácticas sociales hegemónicas antes del encierro, y que se constituyen en referentes discursivos presentes en el espacio local" (p. 260-261). Ese "milagro" es también el punto de partida del ascenso de un "clan" dentro del BNG que tendrá en Anxo Quintana, como ya hemos recordado, su principal exponente.

La práctica que desarrolla el BNG en Fene, en cambio, parte de su relación con la historia del astillero - con la sirena de ASTANO (ahora Navantia) marcando los tiempos de la vida cotidiana-, con un movimiento asociativo potente y con el protagonismo de las "parroquias", singular forma de organización territorial gallega en los municipios. La conquista de la alcaldía por esta formación desde las primeras elecciones municipales de 1979 señala el inicio de un proceso en el que se pasa de una práctica política en la que pesa más la dimensión nacionalista, contestataria y desobediente al Estado y a su simbología, unida al apoyo a las luchas de los trabajadores contra la reconversión del sector naval, a otra en la que, como ya hemos indicado antes, va adquiriendo prioridad la lucha y la gestión de una idea sugestiva de "calidad de vida" (p. 248) en un contexto ya distinto.

Para la autora, por tanto, ambos casos ejemplifican cómo el aumento de votos al BNG ha estado ligado a las distintas formas de articulación de su discurso y de sus prácticas políticas con los contextos locales diferentes a los que ha tenido que hacer frente en las muchas "Galicias". Todo ello relacionado sin duda con la evolución política de una formación que pasó de defender la lucha armada y negarse a ocupar los escaños en su primera irrupción en el Parlamento gallego - para no tener que acatar la Constitución española- a entrar en una lógica de competición electoral que tuvo su momento más álgido con el $25 \%$ de votos que obtuvo en 1997, convirtiéndose en la segunda fuerza política y relegando al PSOE al tercer puesto. Justamente al año siguiente firmaría la llamada "Declaración de Barcelona" reivindicando el reconocimiento de la plurinacionalidad del Estado español, junto con formaciones como el Partido Nacionalista Vasco (PNV) y Convergència i Unió (CiU), de orígenes y trayectorias ideológicas muy diferentes. Una Declaración que tendría su continuidad en nuevos acuerdos con esas mismas formaciones, mostrando así tanto su voluntad de recoger el testigo de la historia de pactos similares con 
los nacionalismos vasco y gallego, como el adoptado en 1923, como su propia aspiración a ampliar su espacio político nacionalista a nuevos sectores sociales.

Se emprendía así un nuevo recorrido que llevaría a la X Asamblea Nacional en 2002, en donde, ya triunfante la lógica competitiva electoral, se opta definitivamente por un partido jerarquizado y por la profesionalización política de la coalición dominante en su seno. Una decisión que no se muestra incompatible con su fuerte presencia en el movimiento de protesta, "Nunca Mais", que se da precisamente ese mismo año contra el desastre ecológico provocado por el hundimiento del barco petrolero Prestige. El paso siguiente será la formación de un gobierno de PSOE y BNG en 2005, con un balance controvertido que no lograría repetirse en las siguientes elecciones autonómicas.

Se abría luego una nueva etapa en la que el proyecto del nacionalismo gallego iría entrando en una profunda crisis, con el posterior declive electoral del BNG, las crecientes divisiones internas en su seno y la irrupción de una coalición electoral entre uno de los sectores escindidos - el encabezado por Beiras - y la organización gallega de Izquierda Unida con ocasión de las elecciones autonómicas de octubre de 2012. Algo inédito, ya que por primera vez una formación nacionalista y otra federalista de ámbito estatal se presentan juntas en unas elecciones autonómicas.

El sorprendente éxito electoral de este nuevo actor político (que obtiene 9 escaños frente a 5 del BNG) no es ajeno tampoco a la capacidad mostrada por esta candidatura para conectar con la nueva generación política que estaba emergiendo ya desde el "Nunca Mais" y luego con el 15M, que, aunque débil en Galicia, supone un desafío al sistema de partidos vigente. La apertura de ese nuevo espacio político y electoral se convertirá en factor determinante del declive del $\mathrm{BNG}$, con mayor motivo cuando en las elecciones municipales de mayo de 2015 surgen nuevas candidaturas, las "Mareas". Éstas lograron rebasar en muchos municipios al BNG para luego impulsar junto con Podemos e IU un "partido instrumental", En Marea, cuyos resultados alcanzados en las recientes elecciones autonómicas del 25 de septiembre de 2016 no han sido los esperados frente a la victoria por mayoría absoluta del PP. Con todo, se ha convertido en la primera fuerza de oposición al Partido Popular, si bien a muy corta distancia del PSOE. En cuanto al BNG, sus resultados han conseguido desmentir los pronósticos de las encuestas ya que basándose en un discurso más nacionalista ha logrado ganar un escaño respecto a los que obtuvo en las pasadas elecciones de 2012 y puede mantener grupo parlamentario propio. Una prueba, a verificar aún con los estudios correspondientes, de que, pese a la evolución y a la crisis sufrida, esta formación sigue contando con un arraigo social notable.

Después de este breve recordatorio por los principales cambios ocurridos tras el periodo analizado en esta obra - y que sin duda nos gustaría que María Lois siguiera abordando en futuros trabajos-, conviene volver a la tesis principal de la autora: la existencia de diferentes visiones, discursos y prácticas políticas que pueden darse desde un común proyecto nacionalista, es decir, desde una aspiración compartida dentro de una misma formación política de construir una nación, en este caso, de construir Galicia(s) como Nación. Considero que ese objetivo, apoyado en una perspectiva de "lugar" que es aplicada exitosamente a dos casos muy 
diferentes, Allariz y Fene, ha sido sobradamente cubierto en este estudio tan "original y valioso", como lo define muy bien John Agnew en el Prólogo a esta obra.

Jaime Pastor Verdú

Facultad de Ciencias Políticas y Sociología, Universidad Nacional de Educación a Distancia

Email: jpastor@poli.uned.es 